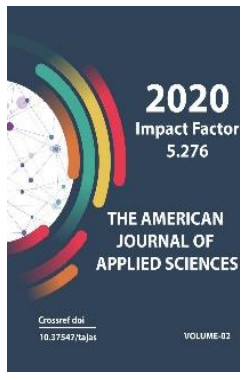

Journal Website: http://usajournalshub.c om/index,php/tajas

Copyright: Original content from this work may be used under the terms of the creative commons attributes 4.0 licence.

\section{Synthesis Of Schiff Bases From Glucosamine On The Basis Of Apis Mellifera}

\author{
Khabibullaeva Nozima, \\ Phd Student Of National University Of Uzbekistan Named After Mirzo Ulugbek, Tashkent, \\ Uzbekistan
}

Khaitbaev Alisher

Professor Of Chemical Department National University Of Uzbekistan Named After Mirzo Ulugbek, Tashkent, Uzbekistan

\title{
ABSTRACT
}

Chitin and chitosan have attained a lot of interest due to their important biological activities and wide range of applications. Traditionally, chitin is prepared mainly from crustaceans. Recently, there has drawn increased attention to extract chitin and chitosan on the basis of insects, but until now only limited numbers of insect species have been documented to be sources of chitin. The main object of this research work is to extract chitosan on the basis of Apis mellifera; to synthesis Schiff bases of glucosamine which is obtained by hydrolysis of chitosan and to review obtained substances through the uses of ICP-MS elemental analysis and IR analysis.

\section{KEYWORDS}

Chitin, chitosan, extraction, hydrolysis, glucosamine hydrochloride, ICP-MS elemental analyze, spectroscopy (IR), Schiff bases.

\section{INTRODUCTION}

Chitin is widespread on Earth as a of animals belonging to the phylum polysaccharide that forms the outer skeleton Arthropoda class (animals with an outer 
skeleton) and forms the cell wall of a certain fungus and algae. Chitin is also, found in the lower flora and fauna and performs several different functions. However, chitosan is less common in nature than chitin and is found only in the cell walls of some fungi [1]. Chitin and chitosan are raw materials for the production of glucosamine, with an annual production capacity of 2,000 and 4,000 tons, respectively [2]. The reserve of chitin in the biosphere is at least 10 Gtons $(1 \times 1013 \mathrm{~kg})$ [3].

Chitin is a linear polymer $(1 \rightarrow 4)$ consisting of 2-acetamido-2-deoxy- $\beta$-D-glucopyranose particles ( $A$ ) that are insoluble in aqueous solvents and have several structural similarities with cellulose., e.g., conformation of monomers and glycoside bonds. Chitosan is a linear binary $(1 \rightarrow 4)$-bound $(A)$ fraction and a 2-amino-2-deoxy- $\beta$-D-glucopyranose fraction copolymer. Glucosamine is obtained by hydrolysis of chitosan in a strongly acidic environment. Glucosamine is an amino monosaccharide with an amino group attached to a glucose ring (2-amino-2-deoxy- $\alpha$ - $D$ glucose) [4]. Glucosamine is a colorless, odorless, and sweet-tasting crystalline substance. It is acidic, has a pH of 3.5-4.5 and a density of $0.75 \mathrm{~g} / \mathrm{ml}$, and is soluble in water. When heated to $80^{\circ} \mathrm{C}$, the Maillard reaction occurs and the color disappears. If heating is continued, glucosamine will begin to burn. Glucosamine has antioxidant and antiinflammatory activity [5]. It blocks the formation of superoxide radicals through macrophages. Its harmful effects have not been identified [6]. Glucosamine that contains nitrogen is an important aminosaccharide found in many tissues of the human body. Unlike carbohydrates, which are the source of energy in the human body, aminosaccharides are found in tissues. Glucosamine is a natural glycoprotein found in the connective tissue and mucous membranes of the gastrointestinal tract [5]. This monosaccharide is involved in the formation of nails, skin, eyes, bones and heart valves. It is also, involved in the biosynthesis of glucosaminoglycans and proteoglycans, which are important for the extracellular matrix of connective tissue. However, the synthesis of glucosamine in the human body decreases with age, and agerelated osteoarthritis begins to develop [7]. Therefore, glucosamine is important in the prevention and treatment of osteoarthritis, and this has been proven by clinical trials [6]. The outer skeleton of marine animals is the main source of glucosamine. It has also been found that synovial fluid contains hyaluronic acid, which provides lubricating and shockabsorbing properties. In the body, glucosamine is synthesized from glucose and glutamine in chondrocytes. Although the Schiff basis of glucosamine has been known since 1922, it has not drawn attention enough. Attention should be paid to the tautomeric and anomeric balance of substances consisting of the Schiff basis and glucose. The structure of some glucosamine Schiff bases was calculated using $\mathrm{ab}$ initio and the tautomer and anomer equilibrium were studied using spectroscopic methods in DMSO solution [8]. Stable complexes of Schiff bases with metal ions such as CU (II), Fe (III) and Co (II) were also obtained from aminosaccharides and salicylaldehyde. These complexes are asymmetric catalysts [9]. Perez obtained Schiff bases with aliphatic ketones of D-glucosamine. The exact stereochemistry of imins has been studied through NOE experiments and DFT calculations [10].

\section{RESULTS AND DISCUSSION}

We used Nexion 2000 ICP Mass Spectrometer, BRUKER Fourier - Spectrometer (4000-450 cm- 
1), Perkin Elmer IR Spectrometer (4000-650 $\mathrm{cm}-1$ ) and IRTracer-100 (SHIMADZU, 2017; $4000-600 \mathrm{~cm}-1)$ in the analysis of the obtained results. Therefore, 2:1 and 2:2 ratio system of ethyl alcohol and acetone, Silifol-UV-254 (KAVALER Czechoslovakia) plates and an iodine chamber as an opener were used for thin-layer chromatography.
The following results were obtained during the elemental analysis of filtrates that is taken in stages I and II to determine the elemental composition of the chitin coating of Apis mellifera:

Table 1. Results of elemental analysis of Apis mellifera.

\begin{tabular}{|c|c|c|}
\hline № & $\begin{array}{c}\text { Phase I } \\
\mathrm{mg} / \mathrm{L}\end{array}$ & $\begin{array}{c}\text { Phase II } \\
\text { mg/L }\end{array}$ \\
\hline Rb 85 & 0.456 & 0.166 \\
\hline Sr 88 & 0.503 & 0.503 \\
\hline Ag 107 & 0.001 & 0.010 \\
\hline Cd 111 & 0.001 & 0.003 \\
\hline In 115 & - & - \\
\hline Cs 133 & - & 0.002 \\
\hline Ba 138 & 0.031 & 0.445 \\
\hline Hg 202 & - & - \\
\hline T1 205 & - & - \\
\hline Pb 208 & 0.015 & 0.074 \\
\hline Bi 209 & 0.001 & - \\
\hline U 238 & - & 0.001 \\
\hline Li 7 & 0.014 & 0.072 \\
\hline Be 9 & - & 0.002 \\
\hline Na 23 & $S$ & $S$ \\
\hline Mg 24 & $S$ & $S$ \\
\hline Al 27 & 1.008 & 25.146 \\
\hline P 31 & $S$ & $S$ \\
\hline K 39 & 93.025 & $S$ \\
\hline Ca 42 & 43.579 & 409.097 \\
\hline V 51 & 0.007 & 0.594 \\
\hline Cr 52 & 0.331 & 0.628 \\
\hline Mn 55 & 0.670 & 7.329 \\
\hline Fe 57 & 6.948 & 172.384 \\
\hline
\end{tabular}




\begin{tabular}{|c|c|c|}
\hline Co 59 & 0.010 & 0.049 \\
\hline Ni 60 & 0.061 & 0.191 \\
\hline Cu 63 & 0.234 & 4.445 \\
\hline Zn 66 & 1.554 & 22.857 \\
\hline Ga 69 & 0.002 & 0.031 \\
\hline Se 82 & 0.017 & 0.120 \\
\hline
\end{tabular}

As can be seen from the aforementioned table, the chitin coating of Apis mellifera does not contain following elements: $\mathrm{Hg}, \mathrm{Tl}$ and In, but $\mathrm{Na}, \mathrm{Mg}, \mathrm{K}$ and $\mathrm{P}$ elements are present in large quantities. These elements occur in the form of salts and provide the strength of the chitin coating [11].

The IR spectrum of chitin which is a product of the deproteinization phase is listed below:

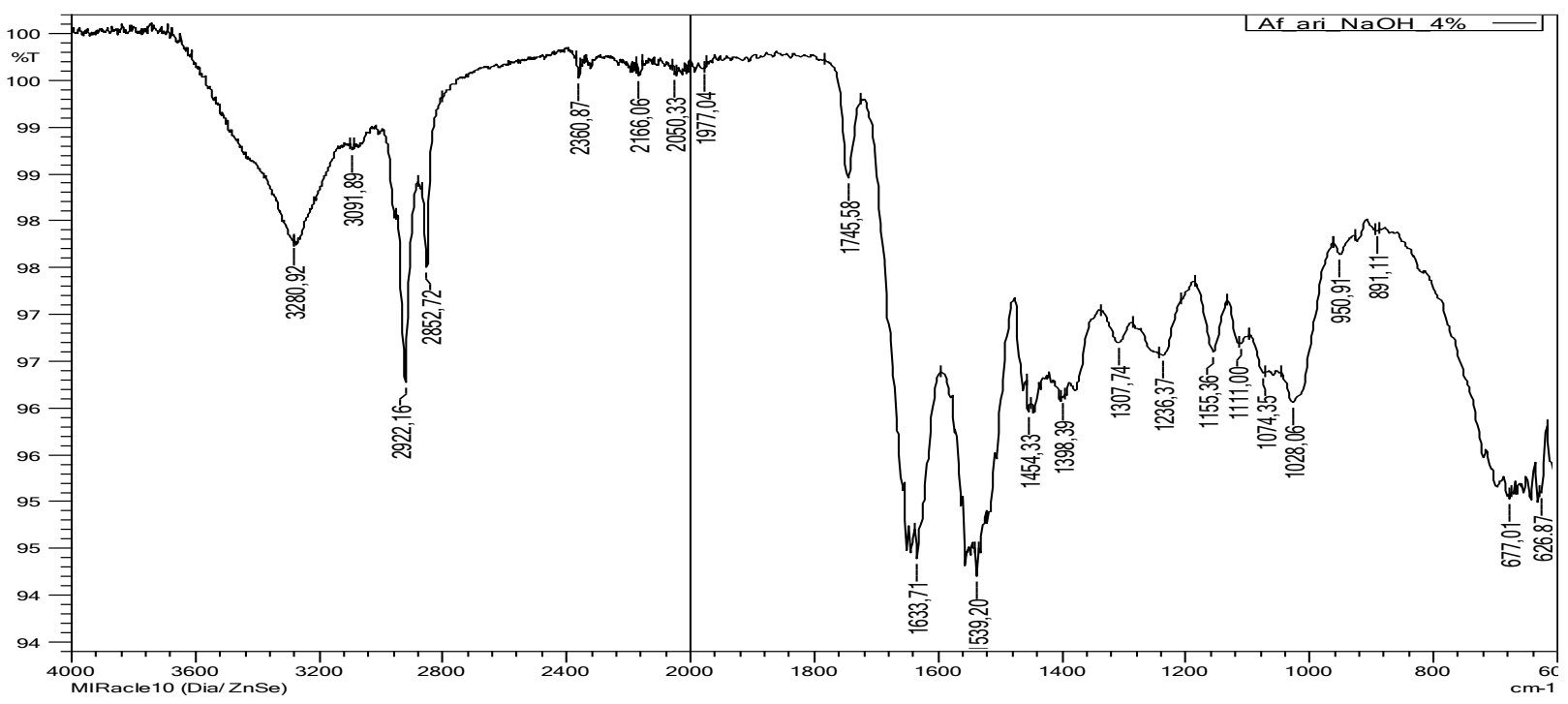

Figure-1. IR spectrum of chitin

In the abovementioned spectrum, amide I and amide II bonds in the chitin substance are observed in the $1539.20 \mathrm{~cm}^{-1}$ and $1633.71 \mathrm{~cm}^{-1}$ regions as an intensive absorption signals. $3280.92 \mathrm{~cm}^{-1}$ region indicates the presence of the $-\mathrm{OH}$ group, $2922 \mathrm{~cm}^{-1}$ region indicates the presence of methylene groups, $1745.58 \mathrm{~cm}^{-1}$ region indicates the presence of the carbonyl group in the acetyl group and $1074.35 \mathrm{~cm}^{-1}$ indicates the presence of the - $\mathrm{C}-\mathrm{O}-\mathrm{C}$ - glycoside bond. We have seen that the results of this spectrum are almost identical compared to the results in the literature [12]. 
In the next step, the chitin is treated with concentrated alkaline solution to take chitosan by means of deacetylation of chitin. The reaction equation and the IR spectrum of the chitosan are given below:

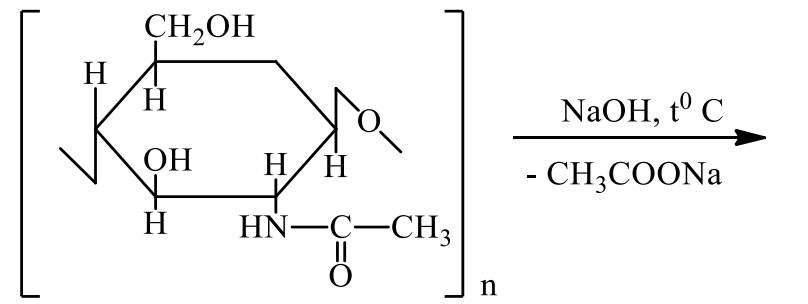

Chitin

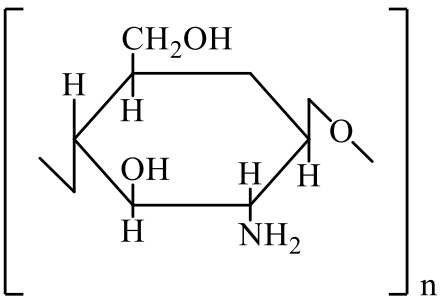

Chitosan

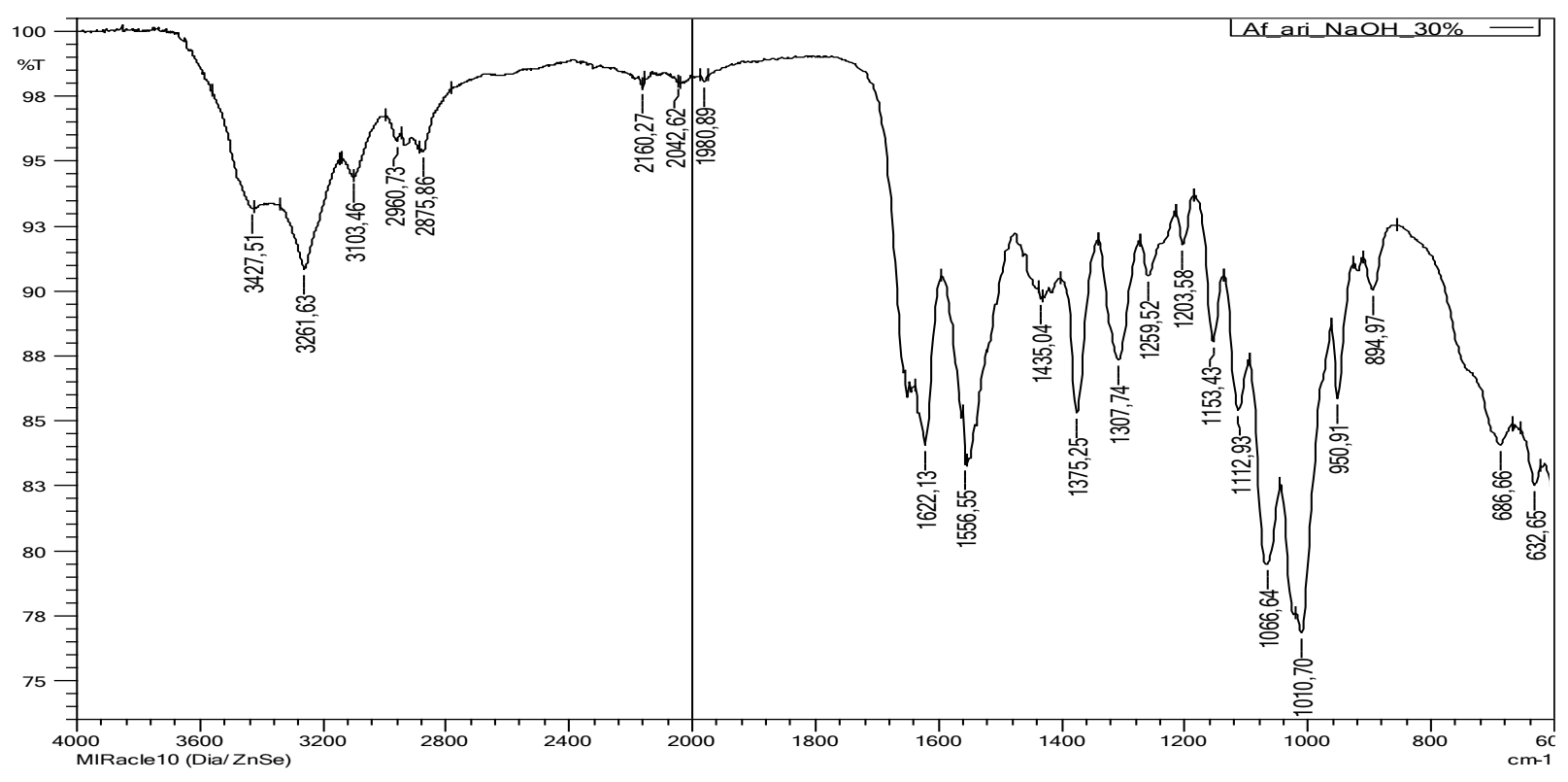

Figure-2. IR spectrum of chitosan

The spectrum of the chitosan was comparable to that of the chitin spectrum, mainly due to changes in the $1556-1622.13 \mathrm{~cm}^{-1}$ region and loss of the signal belonging to the carbonyl group in the $1745.58 \mathrm{~cm}^{-1}$ region due to the release of the acetyl group attached to the amino group. The absorption signal occurring in the 3427.51 $\mathrm{cm}^{-1}$ region belongs to the free amino group.
Then chitosan is hydrolyzed with concentrated acid solution to form a chitosan monomer in the form of glucosamine hydrochloride due to the breakdown of glycoside bonds. The IR spectrum of the obtained substance is described below: 
Doi: https://doi.org/10.37547/tajas/Volume02Issue09-37
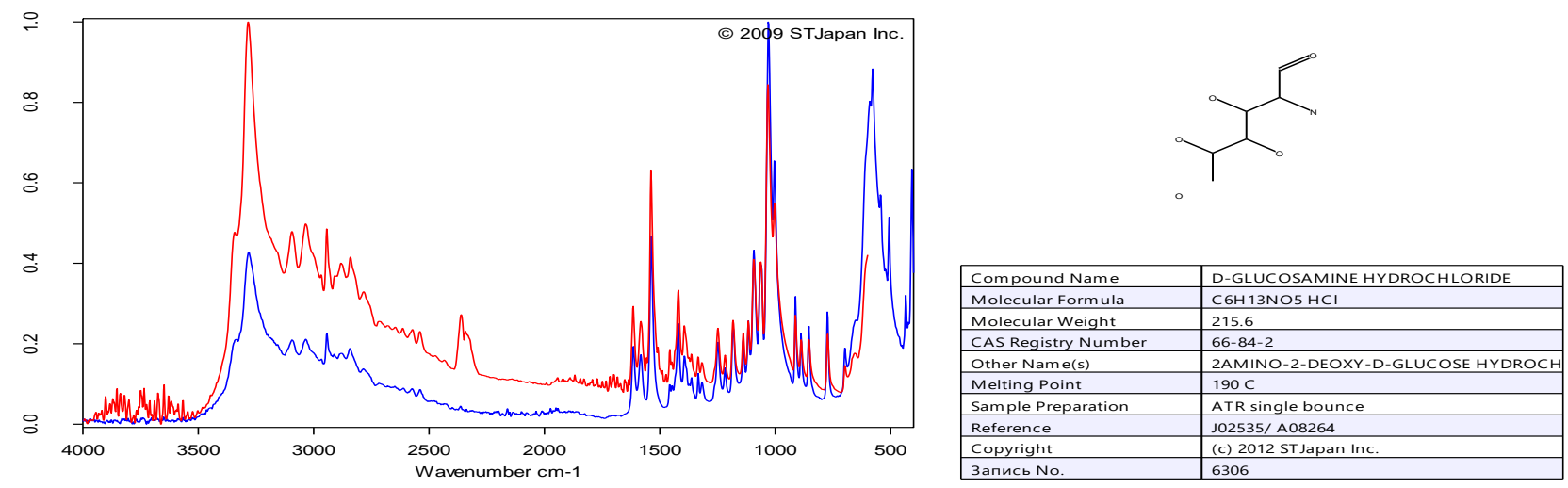

\begin{tabular}{|l|l|l|l|l|l|}
\hline Color & Hit Quality & Compound name & CAS Number & Molecular formula & Molecular weight \\
\hline & 867 & D-GLUCOSAMINE HYDROCHLORIDE & $66-84-2$ & C6H13NO5 HCI \\
\hline
\end{tabular}

Figure 3. IR spectrum of glucosamine hydrochloride

The IR spectrum of glucosamine hydrochloride In final steps, Schiff bases are taken on the is obtained with a BRUKER Fure spectrometer. This spectrum is juxtaposed with glucosamine hydrochloride in the standard state (data basis of indole 3-aldehyde and 6-nitro-1,3-dioxy8-carbaldehyde with glucosamine banks of compounds). Results are shown to be almost identical.

hydrochloride. The reaction equations and the IR spectra of the obtained Schiff bases are dipected below:

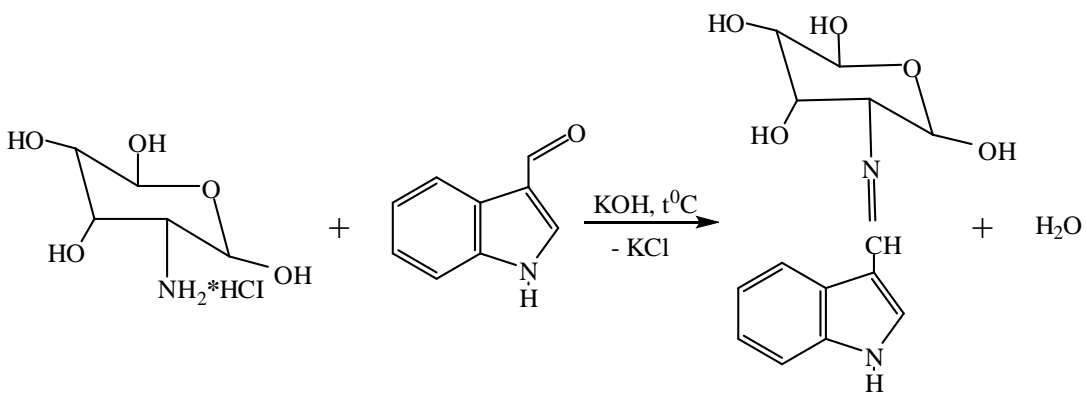

Glyukosamine*HCI Indol-3-aldehyde Schiff basis 


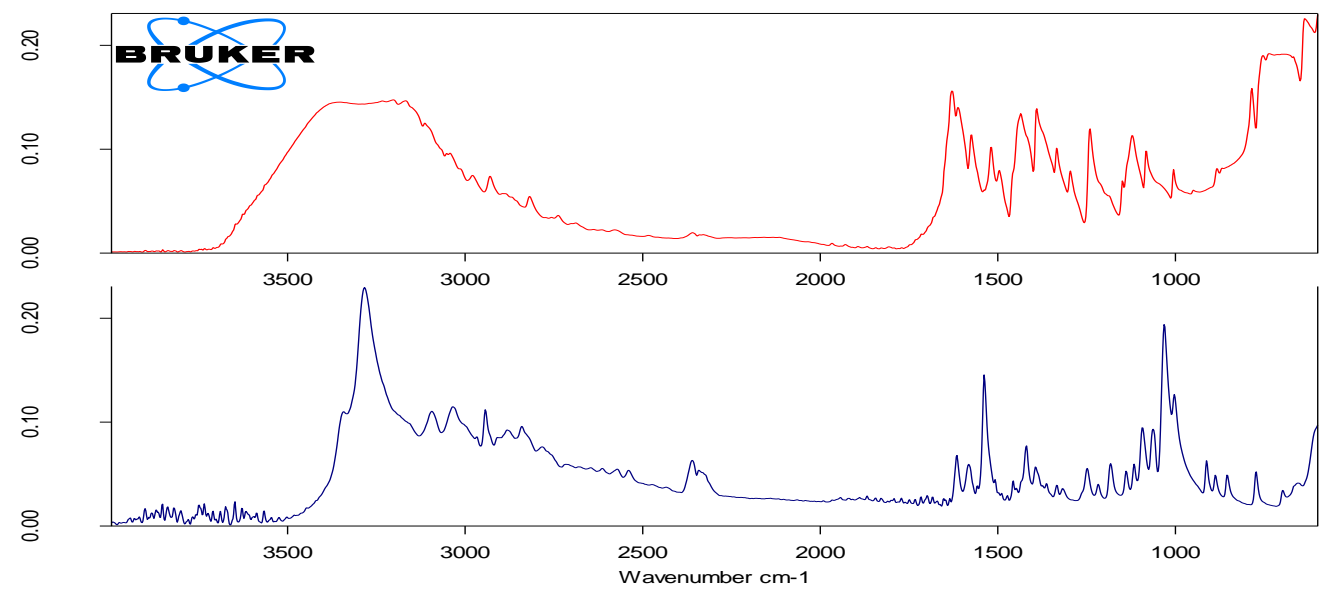

Figure 4. The IR spectrum of Schiff basis of glucosamine with indole 3-aldehyde and glucosamine hydrochloride

Comparing the spectra of Schiff basis with glucosamine hydrochloride, we can see that there is a significant change in the 2800-3700 $\mathrm{cm}^{-1}$ regions and absorption signals are expanded on a Schiff basis due to shielding. Also, the new absorption signal generated in<smiles>O=Cc1cc([N+](=O)[O-])cc2c1OC(O)COC2</smiles><smiles>O=[N+]([O-])c1cc2c3c(c1)C(O)C(O)C(O)/C2=N/C(C(O)O)C(O)OC3O</smiles>

Glyukosamine*HCI 6-nitro-1,3-dioxi -8-karbaldehyde Schiff basis

the Schiff basis at about $1650 \mathrm{~cm}^{-1}$ region was due to the azomethine bond. Changes in the area of $800-1700 \mathrm{~cm}^{-1}$ indicate a reaction. 


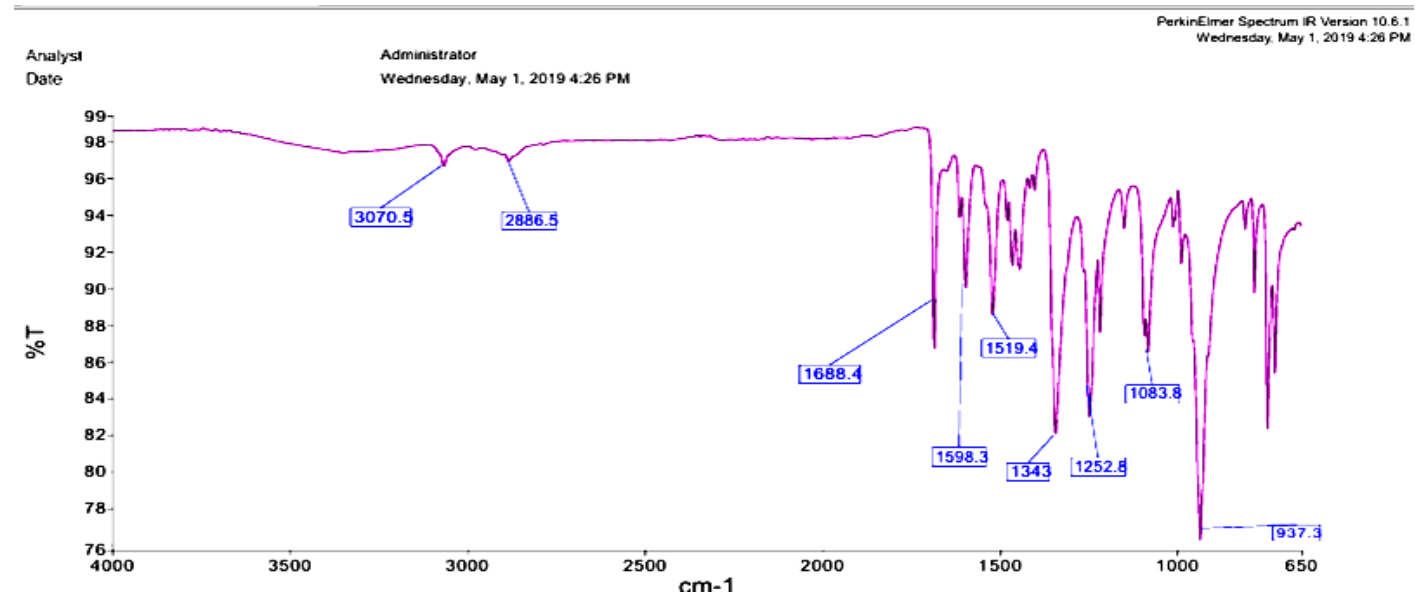

Figure 5. IR spectrum of Schiff basis of glucosamine with 6-nitro-1,3-dioxi -8-

\section{karbaldehyde}

A significant change in the IR spectrum of the Schiff basis compared to the spectrum of glucosamine hydrochloride occurred at 1700$3700 \mathrm{~cm}-1$. It is related to the formation of the azomethine bond and its absorption signal occurred at

$1688 \mathrm{~cm}-1$. Also, changes in the absorption signals that occur in the $650-1700 \mathrm{~cm}-1$ region indicate that a reaction has occurred.

\section{EXPERIMENTAL}

Initially, a certain amount of dried bees was taken and covered with distilled water in a ratio of 1:10. Then heated in a water bath during 1 hour (I) at $70-80^{\circ} \mathrm{C}$, washed and dried using a four-layer filter. The resulting filtrate was analyzed elementally.

The next step was the demineralization step (II), in which $6.5 \% \mathrm{HCl}$ was added to the residue in a ratio of 1:10, heated in a water bath for $1 \mathrm{~h}$, filtered using a Buchner funnel, washed and dried to a neutral medium. The resulting filtrate was analyzed elementally.

In the next phase $7 \% \mathrm{NaOH}$ solution was added to the demineralized substance in a 1:10 ratio, heated in a water bath at $70-80^{\circ} \mathrm{C}$ for $1 \mathrm{~h}$, filtered through Buchner funnel, washed to neutral medium and dried. This stage is called deproteinization, because the protein in the sample is removed and the product is named with chitin (III).

In the next step, chitin is added to $40 \%$ solution of $\mathrm{NaOH}$ in a ratio of 1:10 and heated in a water bath at $70-80^{\circ} \mathrm{C}$ for 1 hour. As a result chitosan is formed due to the release of acetyl groups, this stage is called the deacetylation process.

The resulting chitosan was hydrolyzed in a water bath at $70-80^{\circ} \mathrm{C}$ for 4 hours under the influence of $30 \% \mathrm{HCl}$ solution. Then it was cooled by distilling water and activated charcoal was added. The resulting reaction mixture was heated in a magnetic stirrer for 1 h. and filtered using a Buchner funnel. The acid in the solution was evaporated for $1 \mathrm{~h}$ using a sand bath. The colour of solution is shifted gradually from yellow to brown. Obtained solution was stored in the refrigerator overnight. Thereafter, glucosamine * $\mathrm{HC}_{1}$ in the form of white crystals is formed and derived by filtration. 
Glucosamine hydrochloride was dissolved in distilled water and indole 3 -aldehyde which is dissolved in ethyl alcohol added in the ratio of 1: 1 . Then solution was heated in a magnetic stirrer at $70-80^{\circ}$ for 3 hours. The process was carried out in an alkaline environment. Every 20-30 minutes, the reaction was monitored through thin-layer chromatography. At the end of the reaction, a brown precipitate was formed; the precipitate was filtered and dried.

Glucosamine hydrochloride was dissolved in distilled water and 6-nitro-1,3-dioxy-8carbaldehyde which is dissolved in ethyl alcohol was added to it in a ratio of 1: 1. After, solution was heated in a magnetic stirrer at 70$80^{\circ} \mathrm{C}$ for 3 hours. The process was carried out in an alkaline environment. Every 20-30 minutes, the reaction was monitored through thin-layer chromatography. At the end of the reaction, a brown precipitate was formed. It was filtered and dried.

\section{CONCLUSIONS}

From the results of elemental analysis of substances obtained in the process of extraction of chitin on the basis of apis mellifera, we can conclude that the content of $\mathrm{Na}, \mathrm{K}, \mathrm{P}, \mathrm{Mg}$ and $\mathrm{Ca}$ elements in chitin coating is much higher. The extraction of chitin and then chitosan during the extraction process was analyzed by IR spectra, and these results are almost identical to the results reported in the literature [13], indicating that we have achieved our goal.

In the next step, the spectrum of glucosamine hydrochloride obtained by hydrolysis of chitosan were found to be almost identical when compared with the database. We can also, conclude that the observation of the lightabsorbing signal of the azomethine bond in the
IR spectra of the obtained Schiff bases indicates that a reaction has taken place.

\section{REFERENCES}

1. R. C.Muzzarelli and G.W. Jeuniaux, "Filmogenic properties of chitin/chitosan," in Chitin in Nature and Technology, Eds., pp. 389-396, Plenum Press, New York, NY, USA, 1986.

2. P. A. Sandford, K. M.Varum, A. Domard, and O. Smidsrod, "Commercial sources of chitin and chitosan and their utilization," in Advances in Chitin Sciences, Eds., vol. 6, NTNU Trondheim, Trondheim, Norway, 2003p. 35.

3. C. Jeuniaux and M. F. Voss-Foucart, "Chitin biomass and production in themarine environment," Biochemical Systematics and Ecology, vol. 19, no. 5, 1991, pp. 347-356,

4. El-Saharty, Y. S.; Bary, A. A. Anal Chim Acta 2002, 462, 125.

5. $\quad$ Xing, R.; Liu, S.; Guo, Z.; Yu, H.; Li, C.; Ji, X.; Feng, J.; Li, P. Bioorgan Med Chem 2006, 14, 1706.

6. Jean, Y. R.; Rita, D.; Lucio, C. R.; Richard, L. L.; Eric, L.; Olivier, B.; Giampaolo, G.; Yves, H.; Jane, E. D.; Christiane, G. Lancet 2001, 357, 251.

7. Mc Devitt, C. A.; Muir, H. J. Bone Joint Surg B 1976, 58, 94.

8. Kołodziej B., Grech E., Schilf W., Kamienski B., Makowski M., Rozwadowski Z. and Dziembowska T., Anomeric and tautomeric equilibria in d-2-glucosamine Schiff bases, J. Mol. Struct., 844, 32-37 (2007)

9. Pérez E.M.S., Avalos M., Babiano R., Cintas P., Light M.E., Jiménez J.L., Palacios J.C. and Sancho A., Schiff bases from d-glucosamine and 
aliphatic ketones, Carbohydr. Res., 345, 23-32 (2010)

10. Costamagna J., Lillo L.E., Matsuhiro B., Noseda M.D. and Villagran M., Ni(II) complexes with Schiff bases derived from amino sugars, Carbohyd. Res., 338, 1535-1542 (2003)

11. Khaitbaev A.Kh. Khabibullaeva N.F. Mahkamova N.O./Elemental analysis of Apis mellifera// Materials of the XV International Scientific and Practical Conference CONDUCT OF MODERN SCIENCE -2019// November 30 December 7, 2019/ 106-108 p.

12. Казицина Л.А., Куплецкая Н.Б., Применение УБ, Иқ, ЯМР и массспектроскопии Моск. Ун-та 1979- 240

ст.

13. Thillai Natarajan $S^{*}$, Kalyanasundaram $\mathrm{N}$ and Ravi S. Extraction and Characterization of Chitin and Chitosan from Achatinodes. PG and Research Department of Chemistry, Bharathidasan University, Mannargudi, Tamil Nadu, India.2017. 